\title{
Pediatrik Yaş Gruplarında Akut Ağrının Giderilmesinde Kullanılan Tamamlayıcı Ve Alternatif Tip Uygulamaları
}

Complementary and Alternative Medicine Practices Used For Relieving Pain In Pediatric Age Groups

$$
\text { Şengül Üzen CURA }{ }^{1} \text {, Tanju OĞUL }{ }^{2} \text {, Fatma Yılmaz KURT }{ }^{3}
$$

1. Öğretim Görevlisi, Çanakkale Onsekiz Mart Üniversitesi Hemşirelik AD, Çanakkale, Türkiye

2. Araştirma Görevlisi, Çanakkale Onsekiz Mart Üniversitesi Hemşirelik AD, Çanakkale, Türkiye

3. Yardımcı Doçent Doktor, Çanakkale Onsekiz Mart Üniversitesi Hemşirelik AD, Çanakkale, Türkiye

\section{ÖZET}

Bu araştırma ile Türkiye'de pediatrik yaş grupları üzerinde girişimsel ağr kontrolüne ilişkin Tamamlayıcl ve Alternatif Tip (TAT) uygulamalarının kullanıldığ hemșirelik çalıșmalarının sistematik olarak incelenmesi amaçlanmıştır. Araştırma kapsaminda "tamamlayıcı tıp", alternatif tıp", "çocuk" ve "ağrl", anahtar kelimeleri kullanılarak son 5 yılda (Ocak 2012-Aralik 2016), Türkçe ve İngilizce dillerinde yayınlanan ve tam metnine ulaşılan araştırmalar incelendi. Inceleme sonucunda araştırmalar arasından Türkiye'de pediatrik yaş grupları üzerinde ăgr kontrolüne iliskin TAT uygulamalarının kullanıldi $\breve{g} l$ ve hemşirelik araştırması niteliğinde olan 15 çalışma seçildi. Calıșmanın örneklemini 15 makale olușturdu. Yapılan çalıșmaların; 13'ü randomize kontrollü deneysel, l'i randomize olmayan deneysel, l'i ise yarı deneysel çalı̧̧ma niteliğinde olduğu saptandi. Çalışmaların 14'ünde kullanilan TAT uygulamasinın girişimsel ăgrı üzerine etkisinin ăgrıyı azaltıct yönde olduğu, 1 'inde ise ağrl üzerinde herhangi bir etkiye yol açmadığ tespit edildi. Ülkemizde, son yıllarda pediatrik yaş gruplarında ağrlnın azaltılmasında TAT'tan yararlanıldı ̆̆ görülmesine rağmen TAT'ın daha geniş uygulama sahası bulabilmesi için kanıta dayalı çalışma sayısının artması gerekmektedir.

Anahtar Kelimeler: tamamlayıcı tıp, alternatif tıp, çocuk, ă̆rı

\section{ABSTRACT}

This study aims to systematically investigate nursing studies on the Complementary and Alternative Therapies (CAT) for interventional pain management in pediatric age groups in Turkey. Within the scope of the research, the studies published in Turkish and English languages in the last 5 years (January 2012-December 2016) and found using the keywords "complementary medicine", "alternative medicine", "child" and "pain" were examined. As a result of the study, 15 nursing studies, in which CAT practices had been applied regarding pain management in pediatric age groups in Turkey, were selected. The sample of the study consisted of these 15 articles. Of these studies, 13 were randomized controlled experimental, 1 was non-randomized experimental and the other 1 was quasi-experimental study. It was determined that the CAT practices applied in 14 of the studies were interventional to relieve pain, whereas one of them was found to have no effect on pain. Although CAT has been used to reduce pain in pediatric age groups in Turkey in recent years, it is necessary to increase the number of evidence-based studies for a wider acceptance of complementary and alternative therapies.

Keywords: complementary medicine, alternative medicine, child, pain

\section{iletişim}

Sorumlu Yazar: Yrd. Doç. Dr. Şengül Üzen CURA

Adres: Çanakkale Onsekiz Mart Üniversitesi Terzioğlu Yerleşkesi Sağlık Yüksekokulu, Çanakkale

Tel: +90 (543) 4786662

E-Posta: senguluzen@comu.edu.tr

Makale Geliş: 03.04.2017

Makale Kabul: 02.08.2017

DOI: http://dx.doi.org/10.16948/zktipb.303625

\section{GíRIŞ}

Çocuklarda uygulanan invaziv girişimler, korku ve endişe ile birlikte ağriya da neden olabilmektedir. Ağrı, çocuğun hastalığı ve hastaneye yatışı algılamasını belirgin olarak etkilediğinden mümkün olduğunca en kısa sürede kontrol altına alınmalıdır $(1,2)$. Hemşirelerin, çocuklarda ağrının etkilerini azaltmak ve ağrılı işlemlerin fiziksel ve emosyonel etkilerini gidermek için ağrıyı etkili bir şekilde yönetebilmeleri gerekmektedir. Bunun için en etkili yöntemin seçilmesi gerekir. Son yıllarda yapılan hemşirelik araştırmalarında, çocuklarda ağrı yönetiminde Tamamlayıcı ve Alternatif Tıp (TAT) uygulamalarının kullanıldığı görülmektedir. Tamamlayıcı ve alternatif terapi, bireylerin sağlığını kazanmak için modern tıbbın paralelinde uygulanan yöntemlerin tümüne verilen isimdir. Amerikan Kanser Birliği ve Ulusal Kanser Enstitüsü tamamlayıcı terapileri, modern tıp ile birlikte kullanılan terapiler olarak tanımlamaktadır (3).

Ağrı yönetiminde TAT uygulamaları tek başına kullanıldığı gibi ilaç tedavisine ek olarak da kullanılabilmektedir. $\mathrm{Bu}$ yöntemlerin uygun şekilde kullanıldığında ağrıyı gidermede etkili olduğu görülmektedir. Gelişen teknoloji ile birlikte toplumun TAT uygulamalarına ilgisinin artması sonucu, toplumun sağlık hizmetlerini karşılama amacı taşıyan sağlık profesyonellerinin ve sağlik ekibi üyesi olarak hemşirelerin bu uygulamalarda rol alması bir zorunluluk haline gelmiştir (4). Literatürde, yetişkinlerde ağr1 yönetiminde kullanılan TAT yöntemlerine ilişkin yeterli veri olmasına rağmen, bu uygulamaların çocuklarda kullanımına yönelik bilgiler sınırlıdır. TAT uygulamalarının çocuk sağlığı ve hastalıkları hemşireliği alanında daha geniş uygulama sahası bulup kabul görebilmesi için kanıta dayalı çalışma sayısının arttırılması gerektiğini düşünmekteyiz. $\mathrm{Bu}$ sistematik incelemenin, ülkemizde pediatrik yaş grupları üzerinde ağrı yönetiminde kullanılan TAT uygulamalarının sonuçlarının paylaşıımasına, çocuklar için uygun ağrı yönetiminin belirlenerek konforun arttırılmasına katkı sağlayacağına ve bu yöntemleri uygulayacak olan klinik ve araştırmac1 hemşirelere rehber oluşturacağı kanaatindeyiz. Bu nedenle bu sistematik incelemede Türkiye'de pediatrik yaş gruplarında akut girişimsel ağrıya yönelik TAT uygulamaları ile ilgili son 5 yıl içerisindeki hemşirelik araştırmalarının incelenmesi ve sonuçlarının paylaşılması amaçlanmıştır. 


\section{Araştırma Dâhil Etme Kriterleri}

$\mathrm{Bu}$ araştırmada; çalışma kapsamına alınacak makalelerin seçiminde aşağıdaki kriterler dikkate alınmıştır:

* Türkiye'de yapılmış,

* Tam metine ulaşılabilen,

* Dili Türkçe veya İngilizce olan,

* Son 5 yılda yayınlanmış (Ocak 2012- Aralık 2016),

* Hemșirelik araștırması niteliğinde randomize kontrollü deneysel (RKÇ), randomize olmayan deneysel (RODÇ) ve yarı deneysel çalışma (YDÇ) olan,

* Pediatrik yas gruplarında akut girișimsel ağr1ya yönelik TAT uygulamalarını inceleyen makaleler çalışmaya dâhil edilmiştir.

\section{Çalışmaların Araştırılması ve Seçilmesi}

+ Çalışmanın evrenini PubMed, EBSCOhost, ScienceDirect, ClinicalKey, Scopus ve Google Scholar arama motorları kullanılarak erișilen 1828 makale oluşturdu. İncelemede "Tamamlayıcı T1p", Alternatif Tip" , "Çocuk" ve "Ağrı" anahtar kelimeleri İngilizce karș1lıklarıyla birlikte kullanılarak son 5 yılda (Ocak 2012-Aralık 2016), Türkçe ve İngilizce dillerinde yayınlanan, tam metnine ulașılabilen, RKÇ, RODÇ ve YDÇ'ler tarandı. Bu kriterlere uyan toplam 296 makaleye ulaşıldı. Bu makalelerden Türkiye'de pediatrik yaş gruplarında girişimsel ağrı kontrolüne ilişkin TAT uygulamalarının kullanıldığ1 ve klinik hemşirelik araştırması niteliğinde olan 15 makale tespit edildi ve örneklemi oluşturdu.

Elektronik arama ile saptanan ilgili tüm çalışmaların başlık ve özetleri, araştırmacılar tarafından bağımsız olarak gözden geçirildi. Başlık ya da özetin açık olmadığı durumlarda, çalışmanın dâhil olma kriterlerine uyup uymadığının araştırılması için tam metni incelendi. Araştırmaya dâhil edilmeyen çalışmaların dâhil edilmeme nedenleri Tablo 1'de verildi.

\begin{tabular}{|c|c|}
\hline $\begin{array}{l}\text { Hemşirelik Araştırması Niteliğinde Olmayan RKÇ ve } \\
\text { YDÇ'ler }\end{array}$ & 41 \\
\hline Türkiye'de Yapılmamış Çalışmalar & 1747 \\
\hline Tam Metnine Ulaşılamayan Çalışmalar & 4 \\
\hline Tekrar Niteliğinde Çalışmalar (yayın yapılmış tezler) & 20 \\
\hline TOPLAM & 1812 \\
\hline
\end{tabular}

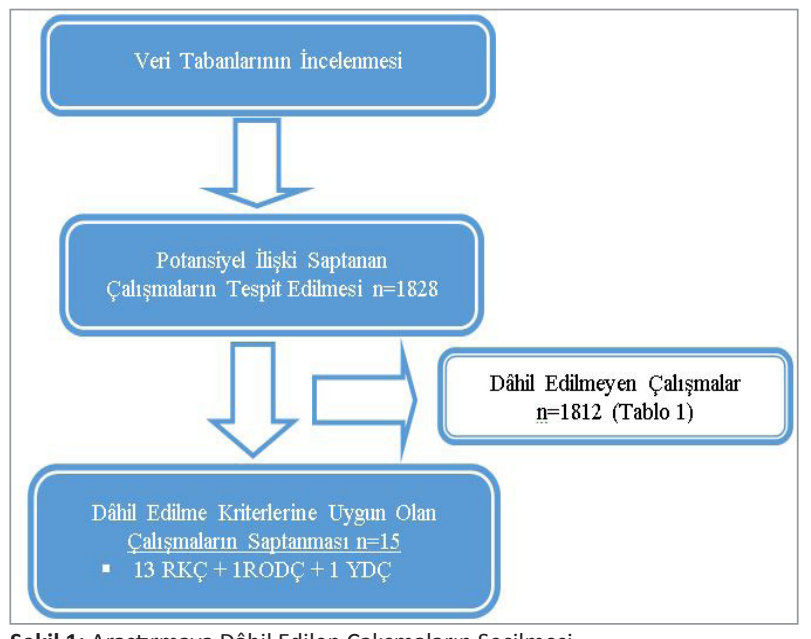

Şekil 1: Araştırmaya Dâhil Edilen Çalışmaların Seçilmesi.
Araştırmacıların incelemeleri daha sonra karşılaştırıldı ve dâhil edilen çalışmaların (Şekil 1) tam metinleri alındı. Araştırmacılar arasında fikir anlaşmazlığ 1 yaşanmadı. Araştırma kapsamında değerlendirilmesi uygun bulunan makaleler; araștırmanın amacı, yöntemi, araştırmada kullanılan TẢT yöntemi ve bu yöntemin ağnı üzerine etkisinin değerlendirildiği sonuç bölümü açısından incelendi.

\section{Verilerin Analizi}

Verilerin özetlenmesi için standart bir veri özetleme formu geliştirilmiş ve veriler buna göre değerlendirilmiştir. Araştırmacıların birbirinden bağımsız olarak dâhil ettikleri çalışmalar, veri özetleme formuna göre özetlenmiştir. Daha sonra özetler karşılaştırılmıs ve araştırmacılar arasında fikir birliği oluşturulmuştur. Veri özetleme formunun içeriği;

* Çalışmanın tasarımı,

* Hangi TAT yönteminin kullanıldığ 1 ,

* Kullanılan TAT yönteminin ağrı üzerine etkisine göre düzenlenmiştir.

$\mathrm{Bu}$ sistematik araştırmaya dâhil edilen çalışmalarda; katılımcıların özellikleri, uygulanan girişim ve ölçüm yöntemleri aynı olmadığından meta-analiz yapılamamıştır. Literatür incelemesinin yapılmasında araştırmacılara herhangi bir maddi/manevi zarar verme riski bulunmamaktadır. Ayrıca incelenen makaleler kaynakçada gösterilmiştir. $\mathrm{Bu}$ sistematik incelemede; Ocak 2012-Aralik 2016 arasında yayınlanan 15 çalışma yer almaktadır. Çocuklarda girişimsel ağrı kontrolüne ilişkin kullanılan TAT uygulamalarının bulunduğu çalışmaların sonuçları Tablo 3'te özet olarak verildi. Tablo 3'te seçilen 15 makale araştırması; araştırmanın amac1, yöntemi, araştırmada kullanılan TAT yöntemi ve bu yöntemin akut ağrı üzerine etkisinin değerlendirildiği sonuç bölümü açısından incelenmiştir. Çalışmaların 14'ünde kullanılan TAT uygulamasının akut girişimsel ağrı üzerine etkisinin ağrıyı azaltıcı yönde olduğu bildirilmiştir. Araştırmalarda uygulanan TAT yöntemlerinin türünün, ilgili yöntem kullanılarak yapılan çalışma sayısının ve ilgili yöntemin girişimsel ağrı üzerine etkisinin yer aldığ 1 Tablo 2 aşağıda verilmiş̧tir.

Tablo 2: Dâhil Edilmeyen Çalışmaların Dâhil Edilmeme Nedenleri.

\begin{tabular}{|c|c|c|}
\hline $\begin{array}{l}\text { Uygulanan } \\
\text { TAT Yöntemi }\end{array}$ & $\begin{array}{l}\text { Çalışma } \\
\text { Sayısı }\end{array}$ & $\begin{array}{l}\text { Girişimsel Ağrı } \\
\text { Üzerine Etkisi }\end{array}$ \\
\hline Masaj Uygulama (5) & 1 & Ağrıda azalma \\
\hline $\begin{array}{l}\text { Balon Şişirme ve } \\
\text { Öksürme Yöntemi (6) }\end{array}$ & 1 & Ağrıda azalma \\
\hline $\begin{array}{c}\text { Dikkati Başka Yöne } \\
\text { Çekme Tekniği }(7,8,9,10)\end{array}$ & 4 & Ağrıda azalma \\
\hline Buzzy Tekniği $(11,12,13)$ & 3 & Ağrıda azalma \\
\hline Refleksoloji (14) & 1 & Ağrıda azalma \\
\hline Mekanik Vibrasyon (15) & 1 & Ağrıda azalma \\
\hline $\begin{array}{l}\text { Uygulama Öncesi İşleme Hazırlık } \\
\qquad(16)\end{array}$ & 1 & Ağrıda azalma \\
\hline Buz Uygulaması (17) & 1 & Etkisi yok \\
\hline Elle Basınç Uygulama (18) & 1 & Ağrıda azalma \\
\hline Fiske Atma (19) & 1 & Ağrıda azalma \\
\hline TOPLAM & 15 & \\
\hline
\end{tabular}


Tablo 3: Pediatrik Yaş Gruplarında Ağııın Giderilmesinde Kullanılan Tamamlayııı Ve Alternatif Tıp Uygulamalarına İlişkin Çalışmalarının Özeti.

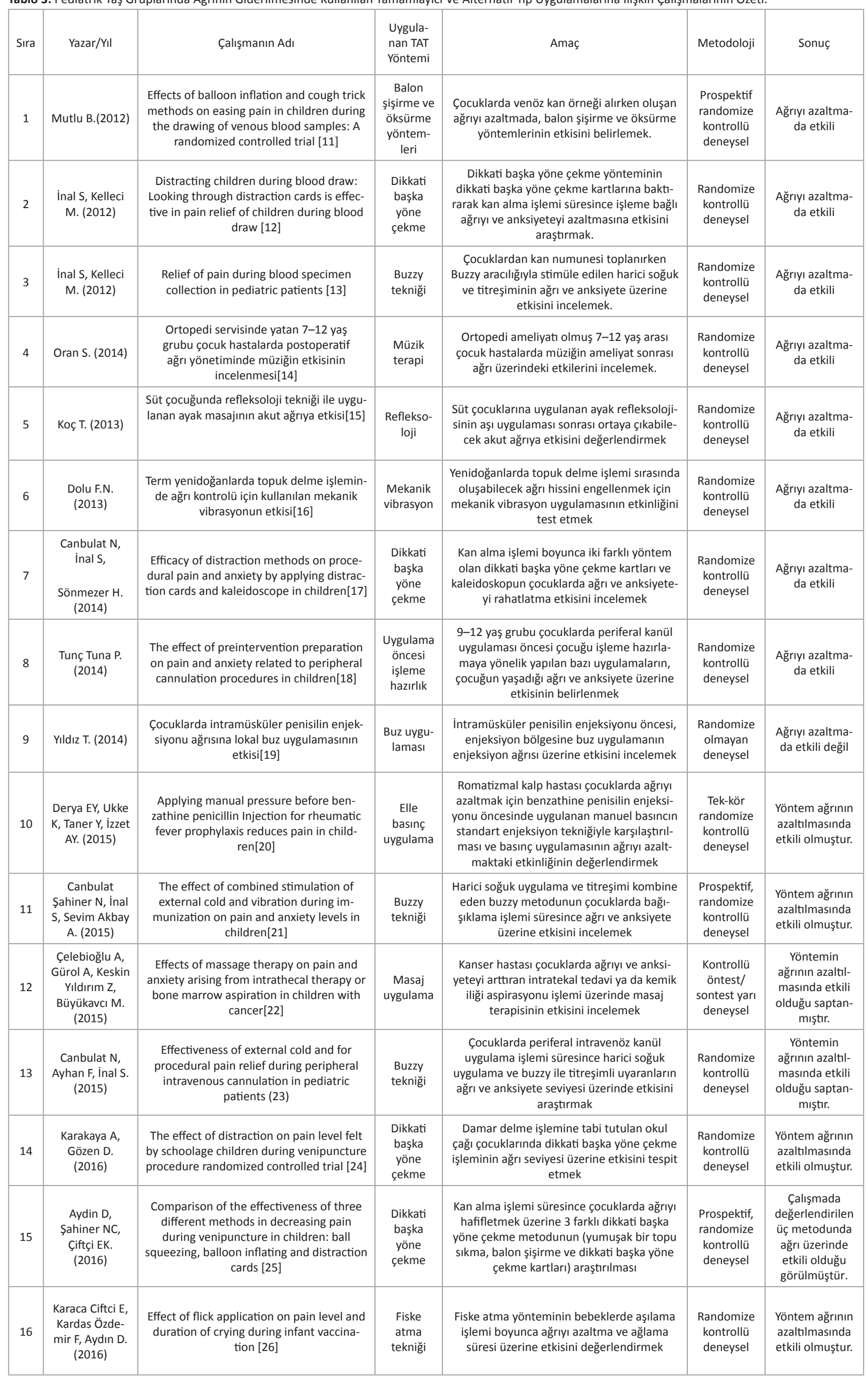


Değerlendirmeye alınan 15 çalışmanın 11'inin son üç y1l içerisinde yayınlandığ́ tespit edilmiştir. Bu durum hemşirelik alanında pediatrik yaş grupları üzerinde yapılmış ağrıya yönelik çalışma sayısında artış olduğunu göstermektedir. Günümüzde yenidoğanlarda ağrı hissinin algılanmadığı düşünceleri yerini yeteri kadar algılanır ancak yeteri kadar değerlendirilemez tartışmalarına bırakmıştır (20). Farmakolojik yöntemlerle birlikte uygulanan TAT yöntemlerinin ağrının hafifletilmesinde ilaçlarının etkinliğini arttırdığ 1 sonucuna varılması da konuyla ilgili çalışma sayısında artışa yol açmış olabilir (21). TAT yöntemlerinin kullanımının hemşirelik alanında yaygınlaşmaya başlamasının bir diğer nedeni de farmakolojik yöntemlerin ağrıyı azaltmakta etkili olduğu fakat bu yöntemlerin ağrıyı azaltmak için tekrar ağrılı bir girişim ile gerçekleştirilmesi ve yan etkilerinin bulunması olabilir (22). TAT uygulamaları invazif olmadığı için çocukların ağrı ve acı hissi duymasina neden olmaz.

Hemşirelik disiplininde kanıta dayalı çalışmaları s1nıflandırmada Stetler ve arkadaşlarının (1998) uyarladıkları kanıt șemasında kanıt gücü bakımından en üst düzeyde kontrollü çalışmalarla meta analizler, deneysel çalışmalar ve yarı deneysel çalışmalar yer almaktadır (23). TAT ile ilgili incelediğimiz çalıșmalarının 14'ünün deneysel 1'inin ise yarı deneysel çalışma niteliğinde olduğu görülmektedir. Hemșirelikte pediatrik yaş grupları üzerinde ağrıya yönelik kanıta dayalı TAT uygulamalarının en üst düzeyde kanıt sağlayacak biçimde planlanması, gerçekleştirilmesi ve daha çok çalıșmanın yapılması gerektiğini düşünmekteyiz. İncelenen deneysel ve yarı deneysel çalışmalar arasında girişimsel işlem öncesi eğitim kitapçığı okutularak işlemin oyuncak üzerinde uygulatılması, masaj uygulaması ve refleksoloji tekniği, dikkati başka yöne çekme, müzik terapisi, fiske atma tekniği, harici soğuk uygulama ve titreşimi kombine eden buzzy tekniği ve elle basinç yöntemlerinin yer aldığı görülmüştür. Bu yöntemler dişında hemşirelerin kısmen uygulamaya dâhil edebildikleri (akupresür, aromaterapi ve teröpatik dokunma gibi) TAT yöntemlerini kapsayan kanıt düzeyi yüksek deneysel/yarı deneysel çalışmalar ile meta analizlerin yapılması gerekmektedir $(24,25)$.

Sonuç olarak; ülkemizde pediatrik yaş grupları üzerinde akut ağrının azaltılması ile ilgili son 5 yılda yapılan TAT uygulamalarının hemşirelik bilim ve sanatı alanında dikkat çekmeye başladığı, ancak daha geniş uygulama sahası bulabilmesi ve hemşirelikte kabul görebilmesi için kanıta dayalı çalışma sayısının arttırılması gerektiği düşüncesindeyiz. Çalışmamız ve sonuçlarının paylaşılması, çocukların ağrılı girişimlerde daha az ağrı yaşamaları ve konforlarının sağlanması açısından önemlidir. Ayrıca hemşirelere ağrılı girişim uygulaması esnasında uygulayabilecekleri tamamlayıc1 ve alternatif uygulamalara ilişkin yol gösterici niteliktedir.

\section{KAYNAKLAR}

Blount RL, Piira T, Cohen L, Cheng PS. Pediatric Procedural Pain. Behav Modif. 2006;30(1):24-49. doi:10.1002/14651858. CD005179.pub3.www.cochranelibrary.com.

2. Uman LS, Birnie KA, Noel M, et al. Psychological interventions for needle-related procedural pain and distress in children and adolescents. Cochrane database Syst Rev. 2013;10(10). doi:10.1002/14651858.CD005179.pub3.www.cochranelibrary.com.
3. Özçelik H FC. Kanser hastalarının tamamlayıcı ve alternatif tedavi kullanım nedenleri. Türk Onkol Derg. 2009;24(1):48-52.

4. Turan N, Öztürk A, Kaya N. Hemşirelikte Yeni Bir Sorumluluk Alant: Tamamlayıc Terapi. Maltepe Üniversitesi Hemşirelik Bilim ve Sanatı Derg. 2010;3(1):93-98. http://hemsirelik.maltepe.edu.tr/dergiler/cilt3sayi1/93-98.pdf.

5. Çelebioğlu A, Gürol A, Keskin Yıldırım Z, Büyükavcı M. Effects of massage therapy on pain and anxiety arising from intrathecal therapy or bone marrow aspiration in children with cancer. Int J Nurs Pract. 2015;21(6):797-804. doi:10.1111/ijn.12298.

6. Mutlu B, Balcr S. Effects of balloon inflation and cough trick methods on easing pain in children during the drawing of venous blood samples: A randomized controlled trial. J Spec Pediatr Nurs. 2015;20(3):178-186. doi:10.1111/jspn.12112.

7. Inal S, Kelleci M. Distracting children during blood draw: Looking through distraction cards is effective in pain relief of children during blood draw. Int J Nurs Pract. 2012:18(2):210-219 doi:10.1111 j.1440-172X.2012.02016.x.

8. Canbulat $N$, Inal S, Sönmezer H. Efficacy of distraction methods on procedural pain and anxiety by applying distraction cards and kaleidoscope in children. Asian Nurs Res (Korean Soc Nurs Sci). 2014;8(1):23-28. doi:10.1016/j.anr.2013.12.001.

9. Karakaya A, Gözen D. The Effect of Distraction on Pain Level Felt by School-age Children During Venipuncture Procedure-Randomized Controlled Trial. Pain Manag Nurs. 2016;17(1):47-53. doi:10.1016/j.pmn.2015.08.005.

10. Aydin D, Sahiner NC, Ciftçi EK. Comparison of the effectiveness of three different methods in decreasing pain during venipuncture in children: ball squeezing, balloon inflating and distraction cards. J Clin Nurs. 2016;25(15-16):2328-2335. doi:10.1111/jocn.13321.

11. InalS, KelleciM.Reliefofpain.Anaesthesia. 2012;37(5):339-345.

12. Canbulat Şahiner $N$, Inal S, Sevim Akbay A. The effect of combined stimulation of external cold and vibration during immunization on pain and anxiety levels in children. J perianesthesia Nurs. 2015;30(3):228-235. doi:10.1016/j.jopan.2014.05.011.

13. Canbulat N, Ayhan F, Inal S. Effectiveness of External Cold and Vibration for Procedural Pain Relief During Peripheral Intravenous Cannulation in Pediatric Patients. Pain Manag Nurs. 2015;16(1):3339. doi:10.1016/j.pmn.2014.03.003.

14. Koç T, Gözen D. The Effect of Foot Reflexology on Acute Pain in Infants: A Randomized Controlled Trial. Worldviews Evidence-Based Nurs. 2015;12(5):289-296. doi:10.1111/wvn.12099.

15. Dolu FN. Term yenidoğanlarda topuk delme işleminde ağr kontrolü için kullanılan mekanik vibrasyonun etkisi. Marmara Üniversitesi. Sağlık Bilimleri Enstitüsü. Yüksek Lisans Tezi. 2013.

16. Tunç Tuna P. Çocuklarda Periferal Kanül Uygulama Öncesi İsleme Hazırlamaya Yönelik Yapılan Uygulamaların Ağrl ve Anksiyete Üzerine Etkisi. TC Eskişehir Osmangazi Üniversitesi Sağlık Bilim Enstitüsü Hemşirelik Anabilim Dalı Cerrrahi Hast Hemşireliği Bilim Dalı Yüksek Lisans Tezi. 2014.

17. Yıldız T. Çocuklarda Intramüsküler Penisilin Enjeksiyonu Ăgrtsına Lokal Buz Uygulamasının Etkisi.Haliç Üniversitesi.Sağlık Bilimleri Enstitüsü.Yüksek Lisans Tezi. 2014.

18. Derya EY, Ukke K, Taner Y, Izzet AY. Applying Manual Pressure before Benzathine Penicillin Injection for Rheumatic Fever Prophylaxis Reduces Pain in Children. Pain Manag Nurs. 2015;16(3):328335. doi:10.1016/j.pmn.2014.08.013.

19. Karaca Ciftci E, Kardas Ozdemir F, Aydın D. Effect of flick application on pain level and duration of crying during infant vaccination. Ital J Pediatr. 2016;42(1):8. doi:10.1186/s13052-016-0218-y.

20. Hutchinson F, Hall C. Managing neonatal pain. J Neonatal Nurs. 2005;11(1):28-32. doi:10.1016/j.jnn.2005.04.006.

21. Dinçer S, Yurtçu M, Günel E. Yenidoğanlarda ă̆rl ve nonfarmakolojik tedavi. Selçuk Üniv Tip Derg. 2011;27(1):46-51. http://selcuktipdergisi.org/files/SUTD-73.pdf.

22. Emir S, Cin Ş. Çocuklarda Ağrl: Değerlendirme Ve Yaklaşim. Ankara Üniversitesi Tıp Fakültesi Mecmuasi. 2004:153-160.

23. Stetler CB, Morsi D, Rucki S, et al. Utilization-Focused Integrative Reviews in a Nursing Service. Appl Nurs Res. 1998;11(4):195-206.

24. Cole A, Shanley E. Complementary therapies as a means of developing the scope of professional nursing practice. J Adv Nurs. 1998; 27:1171-1176.

25. Khorshid L, Yapucu Ü. Tamamlayıcı Terapilerde Hemşirenin Rolü. Atatürk Üniv Hemsirelik Yüksekokulu Derg. 2005;8(2):124-130. 